\title{
La delimitación de los espacios públicos en la necrópolis de Porta Vesuvio en Pompeya (Italia)
}

(7) Noemí Raposo Gutiérrez

(iD) https://orcid.org/0000-0001-9596-0466

Grupo de Investigación HUM 838, Universidad de Huelva. Av. Tres de marzo s/n (CP 21071), Huelva, España. E-mail: noemi.raposo@gmail.com

Recibido: 16 de febrero de 2020 Aceptado: 4 de septiembre de 2020

\begin{abstract}
Resumen
Este estudio se centra en el análisis de la delimitación de los distintos monumentos funerarios que componen la necrópolis de Porta Vesuvio en Pompeya (Italia), así como de los elementos de servicio públicos de la ciudad que se localizan en la necrópolis, como es el acueducto que distribuía el agua a la ciudad. Toda esta delimitación se ha podido analizar gracias a la legislación existente de época romana, así como al estudio de los termini, que son los elementos de demarcación de espacios públicos y privados usados en época romana y que en Pompeya podemos apreciar con claridad, no solo en las tumbas sino en todos los elementos de servicio público localizados en la ciudad. Con este análisis se ha conocido cómo era el sistema de delimitación de una zona suburbana de Pompeya, como es la necrópolis de Porta Vesuvio y, al mismo tiempo, del acueducto que alimentaba a la ciudad, y cómo la urbe cumple la normativa urbana de ocupación de espacios.
\end{abstract}

PALABRAS CLAVE: Zona suburbana; Monumentos funerarios; Tumbas; Acueducto; Termini.

The delimitation of public spaces in the necropolis of Vesuvio Gate, Pompeii (Italy)

\begin{abstract}
This study focuses on the delimitation of tombs in the necropolis of Vesuvio Gate in Pompeii (Italy), and in the public infrastructures located in this necropolis, such as the aqueduct that carried water to the city. This analysis is based on the study of Roman laws, as well as on the study of the termini, which are stones specifically used to delimit public and private spaces in ancient Roman urban areas. The termini can clearly be recognized not only in the tombs but also in the public buildings of the city. This study gives an insight into the system the Romans implemented to define boundaries in the
\end{abstract}


suburban areas of Pompeii, and contributes to our understanding of how urban laws were applied to manage spaces within the city.

KEYWORDS: Suburban area; Funery monuments; Tombs; Aqueduct; Termini.

\section{Introducción: la delimitación de los loca religiosa en la legislación romana}

En Pompeya (Italia) existen evidencias de necrópolis fuera de seis de las ocho puertas que localizamos en la ciudad hasta la actualidad. Sin embargo, no todas las necrópolis están excavadas en su totalidad, por lo que contamos con pequeñas áreas funerarias como la necrópolis de Porta Vesuvio. Aunque no está totalmente excavada, esta necrópolis nos brinda una gran información sobre la forma en que se delimitaban las tumbas y los elementos de servicio público que podrían contener como el acueducto, que alimentaba de agua la ciudad, al igual que los que se encuentran dentro del área urbana. Asimimo, las tumbas constituyen los límites del área urbana, lo que confiere a su territorio un carácter sagrado. Al igual que los demás elementos significativos que bordean el territorio, los lugares religiosos tenían por objeto garantizar la permanencia de los límites en los que se encontraban. Esto creaba un vínculo entre los loca religiosa y las leyes de fundación de las colonias (Hermon, 2017, p. 76).

A las afueras de las ciudades romanas, en ocasiones, se mezclaban la propiedad privada y el mundo fúnebre. En un principio, los romanos enterraban a sus muertos dentro de los recintos urbanos, pero esta práctica fue prohibida y las tumbas se trasladaron fuera de la muralla, junto a las vías de acceso (Castillo Pascual, 2011, p. 118). El establecimiento de los enterramientos dentro de la ciudad fue prohibido desde la ley de las Doce Tablas (Lazzarini, 2005, p. 47; Mommsen, 1899, p. 522), según argumenta Cicerón en su obra: "Hominem mortuum inquit lex in XII in urbe ne sepelito neve urito" (Cic. De leg., II, 58.) (Cicerón, 2009)1.

Por este motivo, en ambos lados de las vías de acceso a la ciudad encontramos cenotaphia, columbaria, mausolea y puticuli o culinae. Junto a este mundo funerario se encontraban los horti, propiedad de los ciudadanos más adinerados o de la misma ciudad y situados también en la zona suburbana, pero más cerca de la ciudad. Eran relativamente pequeños, quizás sin villa, y dedicados a jardines para el reposo y el relax (Castillo Pascual, 2011, p. 118). Además de estos horti, encontramos villas suburbanas y otros establecimientos como, por ejemplo, las termas Suburbanas localizadas a las afueras de la Porta Marina en Pompeya.

Los loca religiosa eran los lugares destinados al culto y consagrados a los dioses Manes, que se encargaban de la protección de los difuntos. Era el lugar donde estaba sepultado un cadáver y solo este sepulcro o tumba era propiedad del titular. Por ello, no se pueden identificar como lugares públicos sino como res religiosae que, al igual que los res sacrae y los res sanctae, formaban parte de las cosas de derecho divino (res divini iuris) (De Marco, 2004, p. 11; De Visscher, 1963, pp. 52-53; Lovato, Puliatti y Solidoro Maruotti, 2014, p. 251); por ello en el Digesto se recoge que "las cosas religiosas no están en los bienes de nadie" (Dig. 1, 8, 6.2; Inst. 2, 1, 7) (D’Ors, 1975).

1 "Al hombre muerto, dice las XII Tablas, no se le sepulte ni se le incinere dentro de la ciudad" (Cic. de leg., II, 58) (Cicerón, 2009). 
Los loca religiosa adquirían tal carácter desde el momento en el que se depositaba un cuerpo o sus cenizas en ellos, siendo condición sin la cual el derecho de propiedad o la plena disponibilidad del suelo no podría existir (Castillo Pascual, 2011, p. 190).

Los loca religiosa eran inalienables, y al igual que los loca sacra estos lugares tampoco eran susceptibles de usucapio, ni de stipulatio, y estaban dentro de la categoría de las res divini iuris; esa es la razón que explica que los agrimensores hablen de una controversia por los lugares sagrados y religiosos (controversia de locis sacris et religiosis). Los loca religiosa eran propiedad particular de una persona o de un collegium y en muchas ocasiones, como lo demuestran las inscripciones, era la res publica y su ordo quienes concedían parcelas de terreno público para las sepulturas (Castillo Pascual, 2011, pp. 191-192; De Visscher, 1963, pp. 65-73).

La concepción del terreno para la construcción de un sepulcro se realizaba por medio de un rito específico a cargo del ius pontificium. En primer lugar, el colegio de los pontífices se dirigía a quien estuviese interesado en la fundación de un sepulcro. La respuesta se pronunciaba, generalmente, por un solo pontífice en nombre del colegio; este organismo se encargaba de tratar los casos de los ciudadanos individuales. Luego se realizaba la elección y delimitación del lugar, según el sistema típico romano de delimitación territorial con termini (Lazzarini, 2005, p. 49).

\section{Los termini: características, usos y legislación}

La colocación de los termini era realizada en conjunto entre los agrimensores, que eran los operadores que se encargaban de hacer las mediciones, y los gromáticos, que eran los encargados de utilizar la groma. Ésta era la herramienta principal que utilizaban los romanos para realizar las mediciones y trazar sobre el terreno las líneas necesarias para la construcción de calles, ciudades, templos, centuriaciones de terrenos agrícolas, etc. Con este sistema posiblemente se iban colocando los mojones para delimitar los lugares públicos y privados tanto dentro como fuera de la ciudad. Los termini seguían un ritual sagrado de colocación, pero no siempre se realizaban estos rituales. El agrimensor Sículo Flaco defiende que era un acto voluntario, porque bajo algunos mojones no hay nada enterrado; pero bajo otros encontramos cenizas, carbones, fragmentos de cerámica o de vidrio, o ases bajo cal o yeso. Este ceremonial nos pone de manifiesto el valor religioso que quería darse a la colocación e inmovilidad de estas piedras, que eran así protegidas no solo por las leyes municipales, sino por creencias y costumbres tradicionales de índole religiosa (Raposo Gutiérrez, 2015, p. 104). De este modo los termini adquirían un carácter sagrado, por lo que eran honrados como si se trataran del mismo dios Terminus (Daremberg, Saglio y Pottier, 1877-1919, p. 123).

Existía una legislación sobre las penas que se imponían a aquel que osara mover dichos termini, disposiciones conocidas como Terminus Motus (Raposo Gutiérrez, 2018a, p. 13). En estas leyes observamos que no había una multa establecida por el crimen de mover los termini, sino que se debía adecuar la pena según la condición social del transgresor (Dig. 47, 21, 1) (D’Ors, 1975).

Por ello, las sepulturas eran solares privados que daban a las vías que marcaban los límites entre propiedades, por lo que ello exigía una delimitación. Éstas funcionaban como si de una domus se tratara, ya que cada particular debía deslindar su propiedad (Raposo Gutiérrez, 2018a, p. 29). Lo que pertenecía a los particulares en el locus sepulturae solía delimitarse con unas inscripciones que contenían las medidas de los espacios sepulcrales que se denomina indicatio pedaturae. Estas inscripciones contenían expresiones que aportaban la longitud de la parcela a lo largo de la vía o 
camino junto al que se situaba: in fronte pedes...; y su anchura, la perpendicular al eje de la vía: in agro pedes... o la medida en general del espacio in pedes quadrati o locus pedum. Generalmente estas inscripciones se encuentran abreviadas: IN F P, IN A P, P $Q$ o L P. que podían indicarse de varias formas: en el mismo monumento funerario con una especie de placa situada en la pared, pintada en la tumba o bien sobre unos termini limítrofes que tenían asimismo la función de delimitar el área sepulcral (Campbell, 2015, p. 100; Castillo Pascual, 2011, p. 63; Cenerini, 2005, p. 137; Vaquerizo y Sánchez, 2008, p. 101; Von Hesberg, 2005, pp. 63-64).

En cambio, algunas tumbas carecían de termini y se precisaban con unos muros (Von Hesberg, 2005, p. 65) denominados maceriae que creaban un recinto sagrado inviolable, y que acapararían la atención del viandante hasta tal punto que, en ocasiones, el monumento funerario quedaba completamente relegado de su función, camuflado en el interior y visible, en algunos casos, gracias a pequeños ventanucos abiertos en el muro de la fachada (Gregori, 2005, p. 81; Ruiz Osuna, 2019, p. 224). Estos muros estaban medidos con el sistema de indicatio pedaturae, y a veces se precisaba también la altura del muro. Ocasionalmente, la maceria contenía también termini sepulcrorum donde figuraban estas inscripciones de mediciones de las tumbas (Gregori, 2005, p. 81).

Aparte de estos termini sepulcrorum, existían otros termini sin inscripciones alrededor de las tumbas que delimitaban el espacio religioso como una zona privada, ya que estos espacios eran zonas abiertas que carecían de protección, sin un guardián que las vigilase (Campbell, 2015, p. 99; Von Hesberg, 2005, p. 65). Según Sículo Flaco era importante distinguir cuáles eran los termini sepulcrorum de los termini de delimitación, dado que se solía construir los sepulcros y colocar los termini sepulcrorum en los linderos extremos y a veces se confundían con los mojones de delimitación. Además de éstos, existían unos termini insertos en las aceras de las vías funerarias que seguían la misma legislación y rituales que los mojones encontrados en las aceras urbanas (Raposo Gutiérrez, 2018a, pp. 34-35). Por lo tanto, su función era delimitar el espacio privado de las tumbas con respecto a los loca publica, que en este caso era la carretera suburbana, cuya violación era una ofensa religiosa y civil que estaba sumamente castigada por la ley.

De esta manera, los loca religiosa eran también utilizados como señales de confines entre propietarios. En una constitución del emperador Tiberio se instituyen los monumentos sepulcrales como monumenta finalia, con un objetivo claro: al carácter de inviolabilidad que tenía un terminus se le unía el que tenía un sepulcro (Castillo Pascual, 2011, p. 192). Por ello, no estaba permitido la invasión y violación de un sepulcro y quien lo hiciera debía recibir una multa. Existen una serie de leyes en el Digesto sobre la prohibición de violar un sepulcro y las penas que se imponían al trasgresor como: “La acción de violación de sepulcro es infamante" (Dig. 47, 12, 1) (D’Ors, 1975).

El crimen de violar un sepulcro puede decirse que está previsto en la ley Julia sobre los actos de violencia <<privada $>$, allí donde se trata del que hiciera algo que impidiera a alguien los actos de funerales y entierro, pues el que viola un sepulcro viene a dejar insepulto al allí enterrado (Dig. 47, 12, 8) (D’Ors, 1975).

Dice el pretor: Daré acción contra aquel con cuyo dolo malo se diga haber sido violado un sepulcro, para que sea condenado por ello, a favor del titular del mismo, en lo que parezca justo. Si no se halla titular alguno, o éste no quiere demandar, por valor de cien áureos. Si varios quieren demandar, daré facultad para hacerlo a aquel cuya causa para hacerlo parezca más justa. Si alguien habitara con dolo malo en el sepulcro o hubiera edificado algo ajeno al sepulcro, daré acción contra él, por valor de doscientos áureos, a quien quiera demandar por esa causa (Dig. 47, 12, 3) (D'Ors, 1975). 
Aparte de la legislación sobre la delimitación de las tumbas, existía otra fórmula por la cual se reglamentaba el espacio funerario usado para los sepelios dentro de las necrópolis. Esta delimitación consistía en la regulación del uso del espacio público por parte de algunos ciudadanos, destinados sobre todo a sacerdos publica y a tribunus militum ab populos. Éstos construían sus tumbas en zonas públicas dentro de las necrópolis; estas áreas pertenecían a la ciudad y sin un permiso expreso del ordo decurionum no podía construirse nada en ese espacio público (Campbell, 2015, p. 84).

El permiso consistía en que el ciudadano solicitaba a los magistrados el uso de esa zona pública dentro de la necrópolis para construir en ella su monumento funerario y si el ordo le concedía el permiso se ponía en la tumba una inscripción que contenía la frase: ex decreto decurionum (EDD) ${ }^{2}$, es decir, "por decreto de los decuriones" o "con permiso de los decuriones" (Campbell, 2015, p. 84). No obstante, tradicionalmente desde principios del siglo XX, estudios sobre Pompeya han defendido que esta frase impuesta en las tumbas indicaba una donación por parte del ordo decurionum hacia un ciudadano difunto, para honorificarlo por alguna acción bondadosa o reconocer el estatus de esa persona ante toda la ciudad. Sin embargo, no regalaba el suelo público sino que prestaba el uso de esta tierra, por lo que la propiedad poseída no formaba parte del patrimonio del poseedor y no era declarada como propia sino de la ciudad. Lo que se cede, por lo tanto, no es ni un derecho ni la tierra, sino el uso de ésta. Finalmente, este simple disfrute no era susceptible de usucapio, contrariamente a los deseos de los poseedores (Moatti, 1992, p. 65).

Otros autores han argumentado también que estos monumentos funerarios ubicados en el pomerium no eran tumbas propiamente dichas sino memoriales, porque no existen evidencia de sepelio, sino que eran monumentos que servían para honorificar al difunto, cuyos restos no se guardaban en ellos. Esta teoría fue iniciada por Mau en 1908, aunque no aporta datos que respalden su hipótesis; no obstante, varios autores han apoyado dicha teoría durante todo un siglo (Carroll, 2006, p. 139; Clarke, 2003, p. 182; Cooley y Cooley, 2004; Jacobelli, 2001, pp. 51-52; Lassère, 2005, pp. 392-393; Ling, 2005, p. 79; Mau, 1908, pp. 427-449; Richardson, 1989, pp. 363-366; Toynbee, 1971, pp. 119-124).

Sin embargo, añadimos que no solo existía la frase: Ex Decreto Decurionum, sino que en algunas tumbas encontramos la frase: Pecuniam Publica Decreto Decurionum (PPDD), es decir, "(Pagado con dinero) público con permiso de los decuriones". Esto indicaba una honorificación del difunto, ya que manifiesta que la construcción de un elemento en un espacio público era costeado por la ciudad, posiblemente porque había realizado un acto importante que era necesario reconocer (por lo que era un gran honor para el fallecido y su familia), pero ello no se interpreta como una donación, dado que el permiso era obligatorio que fuera realizado con una contribución económica pública o privada porque la propiedad del suelo era de la ciudad (Campbell, 2015, p. 89). 0 bien la frase: Locus Datus Decreto Decurionum (LPPP) ${ }^{3}$, que indicaba el uso del suelo público por un privado y que éste podía construir en él con sus propios medios, pero la propiedad siempre estaba en manos de la ciudad (Jacobelli, 2001, p. 53).

No obstante, esta frase la podemos encontrar en otros elementos que no tienen un carácter funerario, como es el caso de las esculturas honoríficas situadas en el Foro Civil, ya que al igual que las tumbas se construían en terreno público como era la plaza del Foro Civil (Raposo Gutiérrez, 2018a, pp. 191-192). También la encontramos en estatuas situadas en los distintos templos de la ciudad, como es el caso de las esculturas del Templo d'Iside, que contaban con el permiso de los decuriones, ya que

2 "Con permiso de los decuriones".

3 "Lugar dado con permiso de los decuriones". 
en lugares sagrados tampoco se podía colocar ningún elemento sin autorización como en los loca publica (Raposo Gutiérrez, 2017, pp. 296-297). Por último, se encuentran también inscripciones con este mismo permiso en edificios públicos de ocio de Pompeya, como en el teatro donde algunos magistrados compraron unos asientos con el permiso de los decuriones; una situación similar hallamos en el anfiteatro, donde un grupo de magistrados, entre ellos los magistri del Pagus Augustus Felix Suburbanus, pagaron la instalación de unos asientos en la cavea del anfiteatro con el permiso de los decuriones (Raposo Gutiérrez, 2017, p. 360; Raposo Gutiérrez, 2018b, p. 118).

Por consiguiente, defendemos la teoría de Campbell, en la que argumenta que el ciudadano que pretendía construir una tumba en terreno público, es decir en el espacio que estaba situado dentro de los $30 \mathrm{~m}$ desde la puerta de la ciudad y que posiblemente correspondería al área del pomerium de la ciudad, en el cual no estaba permitido construir ningún elemento, tenía que solicitar un permiso a los magistrados antes de empezar a erigir el monumento funerario (Campbell, 2015, pp. 84-85), al igual que ocurría en otros espacios públicos de la ciudad. Si el permiso le era concedido podía proceder con la edificación de la tumba estando con ello exento de multa; por el contrario, si no le era concedido, el ciudadano no tenía autorizada la construcción de elemento alguno, bajo pena de sanción por la fundación indebida de un monumento funerario en terreno público. En todo caso, construir una estructura tan cara a nivel económico como una tumba, probablemente no ameritara tomar el riesgo de desafiar a los decuriones haciendo algo sin permiso (Campbell, 2015, p. 92), para que luego, además de la sanción, procedieran a destruirla como se argumenta en el Digesto: "Si alguien hubiera edificado en lugar público sin que nadie se lo impidiera, no se le debe obligar a que derribe, pues no hay que afear la ciudad con ruinas, y el interdicto es prohibitorio pero no restitutorio; pero si tal edificio estorba al uso público, es cierto que el procurador de las obras públicas deberá abatirlo o, si no estorba, imponer un solario" (Dig. 43, 8, 2.17) (D'Ors, 1975). Por lo tanto, llegamos a la conclusión de que ésta era una frase muy común en el mundo romano, ya que para construir algo o realizar cualquier modificación en terreno perteneciente a la ciudad era necesario un permiso de los decuriones.

\section{La delimitación de los espacios públicos en la necrópolis de Porta Vesuvio}

Si seguimos la línea de muralla desde la necrópolis de Porta Ercolano hacia el lado Este de la ciudad encontramos la necrópolis de Porta Vesuvio, que conecta con la ciudad a través de la Via del Vesuvio (Figura 1). La necrópolis de Porta Vesuvio se comenzó a excavar en enero de 1907. Sin embargo, estos primeros trabajos fueron rápidamente suspendidos y retomados en 1908 hasta el año 1910. En este espacio salieron a la luz cuatro sepulcros y también el ramal del acueducto que portaba el agua a la ciudad de Pompeya y se conectaba con el Castellum Aquae para ser distribuida a la ciudad (Spano, 1910, pp. 399-401; Stefani, 1998, p. 43).

En trabajos de excavación realizados unos años antes, entre 1897 y 1900, habían aparecido restos de estructuras, que tendrían relación con el área suburbana de la necrópolis de Porta Vesuvio. Estas zonas se encuentran al noreste y noroeste de la muralla y se conocen como Fondo Masucci d'Aquino y Fondo Barbatelli. En estas dos áreas aparecieron restos de estructuras que parecen pertenecer a la villa de T. Siminius Stephanus, ya que se encontró, en el peristilo del complejo, un sello de bronce en el que estaba escrito dicho nombre (Sogliano, 1899, pp. 236-237; Stefani, 1995, pp. 12-13). Esta villa está compuesta por un propileo de columnas, que tienen la función de entrada a la residencia, y numerosas estancias todas alrededor de un patio y con un peristilo. Además, contiene una estructura que se interpreta como un espacio destinado a una actividad artesanal, concretamente el taller de un broncista en el que se realizaban 


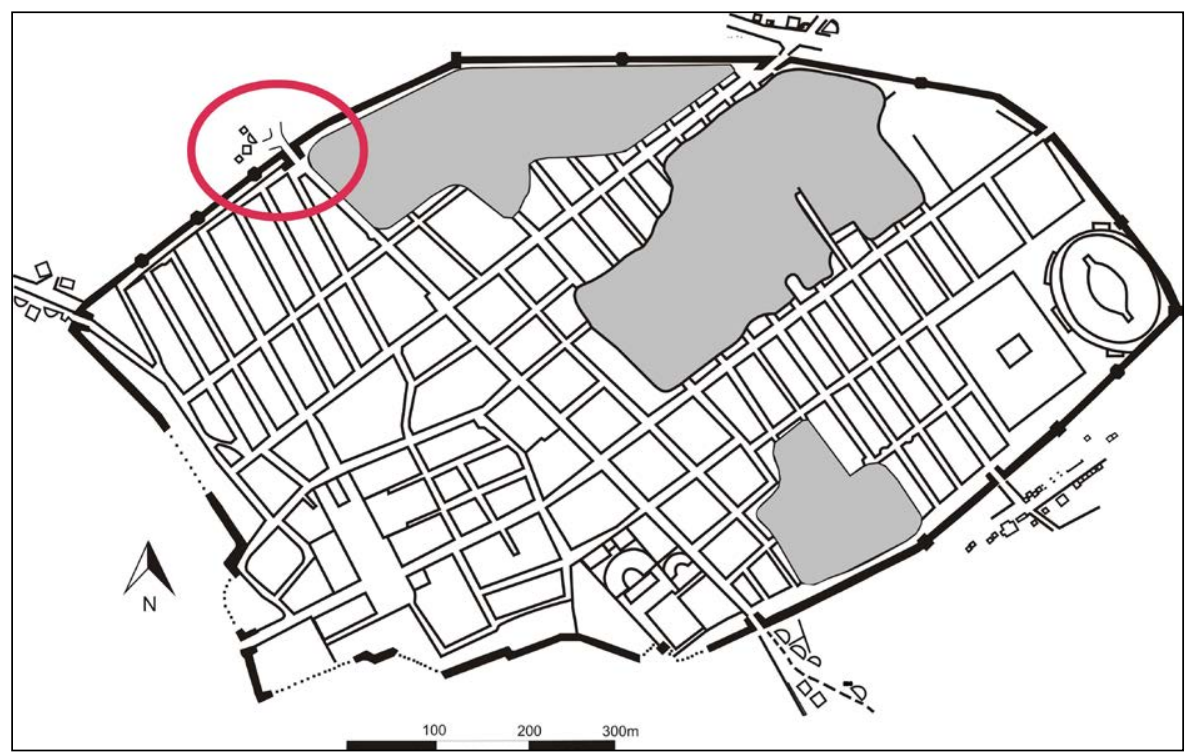

Figura 1. Plano de ubicación de la necrópolis de Porta Vesuvio.

vasos de metal, se modificaban estatuas de bronce, etc. (Sogliano, 1899, p. 237; Stefani, 1995, pp. 24-25).

Al no estar excavada en su totalidad, no podemos saber si esta necrópolis consiste también en un barrio extraurbano, como la necrópolis de Porta Ercolano, que contaba con el Pagus Augustus Felix Suburbanus en el que existen distintas tabernae y villas suburbanas. No obstante, se tiene constancia de que esta carretera sepulcral no llegaba a ninguna ciudad importante como la de Via dei Sepolcri, que enlazaba con el núcleo de población de Herculano, sino que conectaba con los campos y las villas de los agricultores que vivían en los alrededores de Pompeya a los pies del monte Vesubio como con la villa de T. Siminius Stephanus (Stefani, 1995, p. 25).

Esta necrópolis carece de aceras, aunque no sabemos si es porque no está excavada en su totalidad, porque no se conservan o porque no se construyeron. Pero si la confrontamos con otras necrópolis de la ciudad, todas contaban con aceras, y en concreto, si la comparamos con la necrópolis de Porta Stabia y Porta Nola, que tampoco están excavadas en su totalidad, éstas sí tienen aceras (D'Ambrosio, 2001-2002, p. 220; Raposo Gutiérrez, 2017, p. 391). Sin embargo, sí hay una zona que cuenta con acera, concretamente en el lugar donde se situaba la Porta Vesuvio, que es la acera que corresponde al acceso peatonal de la puerta (Raposo Gutiérrez, 2018c, p. 276). Esta acera conecta con la necrópolis de Porta Vesuvio, pero no continúa por la necrópolis.

En la necrópolis se observa una calzada pavimentada, y justo en el lado en el que se encuentra la acera de la Porta Vesuvio se observa una línea de bordillos que bordean la muralla hacia el Oeste con una longitud de $8,50 \mathrm{~m}$ y separados de la muralla entre 3,50 y $5 \mathrm{~m}$ de la muralla (Figura 2). Se podría hipotizar que fuera una acera, pero se piensa que eso no es posible ya que no se podía adosar nada a la muralla de la ciudad, porque era el sistema defensivo de la urbe. Pese a ello, la muralla y el pomerium de Pompeya sufrieron algunas invasiones: en la zona Suroeste, por parte de algunos propietarios con la construcción de sus viviendas, y por otro lado fue invadida por el templo de Venus, en la zona Sureste por el anfiteatro (Raposo Gutiérrez, 2018c, p. 279), y en la necrópolis de Porta Ercolano por la tumba de Marcus Cerrinius Restitutus que se adosa a la muralla, las tumbas de Aulus Veius y la tumba de titularidad desconocida, que se le conoce como PE 1, que invaden el pomerium de la ciudad. Tenemos constancia de que 


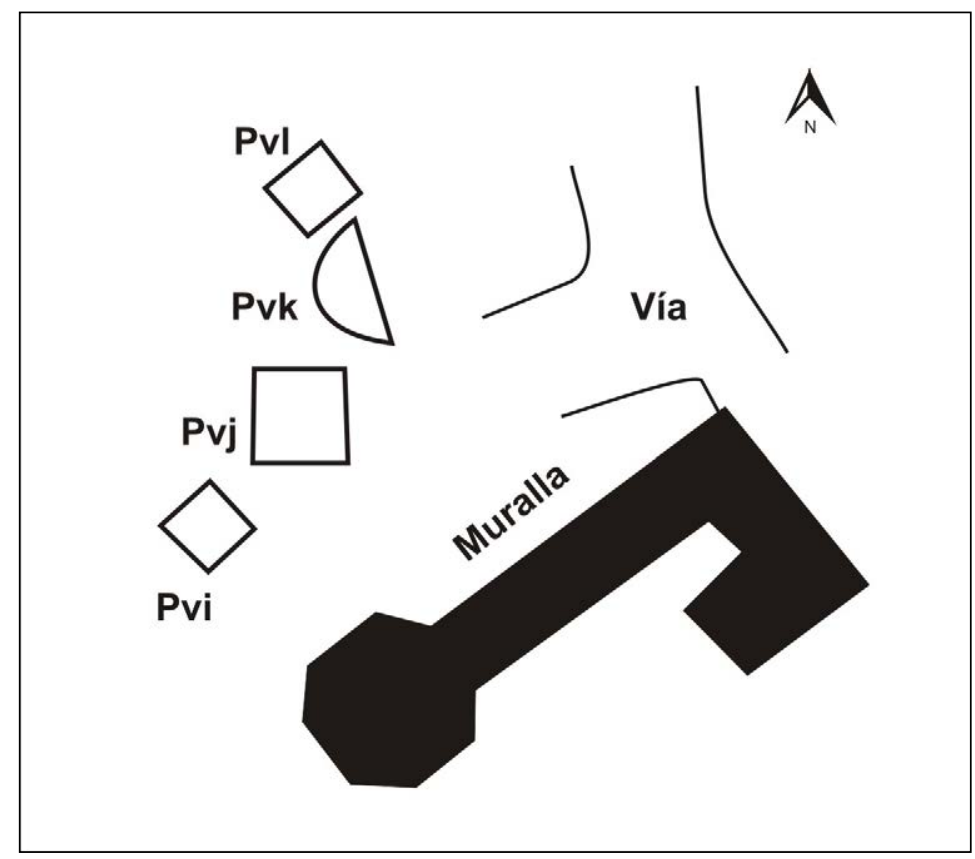

Figura 2. Plano de localización de las tumbas de la necrópolis de Porta Vesuvio. Referencias: Pvi: Tumba perteneciente a Marcus Veius Marcellus; Pvj: Tumba perteneciente a Caius Vestorius Priscus; Pvk: Tumba perteneciente a Arellia Tertulla y Pvl: Tumba perteneciente a Septumia. Elaboración propia.

estas tumbas que avanzan en estos espacios o que se adosan a la muralla contaban con permiso de los decuriones de la ciudad, según se aprecia en las inscripciones que se conservan (Raposo Gutiérrez, 2017, pp. 381-384). Sin embargo, con respecto a las invasiones de las residencias de los particulares, del anfiteatro y del templo de Venus no contamos con evidencias que nos demuestren que dichas invasiones fueran permitidas. No obstante, se piensa que los magistrados de la ciudad permitieron que estas construcciones se adosasen a la muralla o incluso la rebasaran, en el momento en el que Pompeya ya era colonia romana y la muralla hubiera perdido importancia como sistema defensivo, ya que la ciudad estaba dentro del dominio romano y no había peligro de ser asediada nuevamente. A pesar de ello, si este hubiera sido el motivo, los magistrados de la ciudad optaron por no cumplir la ley urbanística en los espacios defensivos y habría sido un problema si se hubiese producido algún ataque a la ciudad (Raposo Gutiérrez, 2018c, pp. 279-280).

A pesar de que se produjeron algunas invasiones a la muralla, se piensa que esta estructura podría tratarse de un elemento demarcador del espacio de la calzada para destacar su trazado por la necrópolis, ya que no tiene sentido establecer una acera en la muralla. Además, si lo comparamos con otras necrópolis de la ciudad, no se localizan aceras adosadas a la muralla. Lo que se encuentra es que la acera urbana continua en la zona suburbana, tanto en la necrópolis de Porta Ercolano (Raposo Gutiérrez, 2017, p. 369) como a la salida de la Porta Marina, continúa delante de las termas suburbanas (Raposo Gutiérrez, 2018a, p. 181).

La necrópolis de Porta Vesuvio cuenta con 4 monumentos funerarios excavados, que están delimitados por termini. Éstos tienen un mayor tamaño que los que se encuentran en la zona urbana y en otras necrópolis de la ciudad. Las tumbas de esta necrópolis, además de estar delimitadas por termini, se demarcaban con recintos amurallados llamados maceriae. Esta era una tipología muy difusa en el siglo I d.C. en Pompeya y en otras zonas del Imperio. Son tumbas muy recurrentes sobre todo en la necrópolis de Porta Ercolano y Porta Nocera (Mols y Moormann, 1993, p. 39). 
Esta necrópolis fue estudiada por Spano (1910), el cual estableció un sistema de siglas para nombrar a los monumentos funerarios de modo que resultara más fácil su identificación (Figura 2). En la actualidad, este es el sistema que se sigue usando, por lo que es el que se va a utilizar para identificar las tumbas en este análisis. Estos sepulcros, a diferencia de los de la necrópolis de Porta Ercolano, estaban separados unos metros de la muralla, pero aun así se observa como algunas tumbas estaban situadas en suelo público. Esto se aprecia en las inscripciones que se conservan en los monumentos funerarios: el suelo fue cedido con permiso de los decuriones para que algunos ciudadanos notables pudieran construir sus monumentos funerarios cerca de la puerta, como un hecho de distinción social.

El primer monumento sepulcral que nos encontramos es la tumba PVi perteneciente a Marcus Veius Marcellus (Figuras 2 y 7). El fallecido pertenecía a una familia próspera y adinerada, por lo que sería rápidamente magistrado de Pompeya. Este sepulcro tiene como característica que es una construcción asimétrica, es decir, los muros no tienen las mismas medidas ni de ancho ni de largo. No hay evidencias de la fecha de la tumba o de fallecimiento en las inscripciones que ésta contiene (Campbell, 2015, p. 200; Emmerson, 2011, p. 187; Wesch-Klein, 1993, p. 142) pero se piensa que esta tumba se construyó entre los años 62-79 d.C., según los análisis arquitectónicos de la tumba y los grafitos que se encuentran a lo largo de los muros de la ciudad en los que aparece el nombre del magistrado al que está dedicado el monumento funerario. Sin embargo, se cree que en ese período Marcus Veius Marcellus aún no había fallecido, porque no hay evidencias de estructuras para sepelio dentro de la tumba. Por ello, existe la hipótesis de que el sepulcro habría sido donado a este magistrado en vida; así, en el año 79 d.C. posiblemente esta persona estaba viva y la tumba se construyó para que en un futuro fuera usada por este individuo. Es probable que se hiciera un sepulcro más elaborado y no tan asimétrico, ya que se cree que se construyó para reservar ese espacio y que no fuera ocupado por otra persona (Campbell, 2015, p. 201). Este monumento funerario se encuentra delimitado por un muro a modo de maceria, pero también estaba demarcado por termini bastante gruesos (Figura 3), y contiene una inscripción en la que expone que se le concede ocupar esta área con permiso de los decuriones (Figura 4) (Spano, 1910, p. 403).

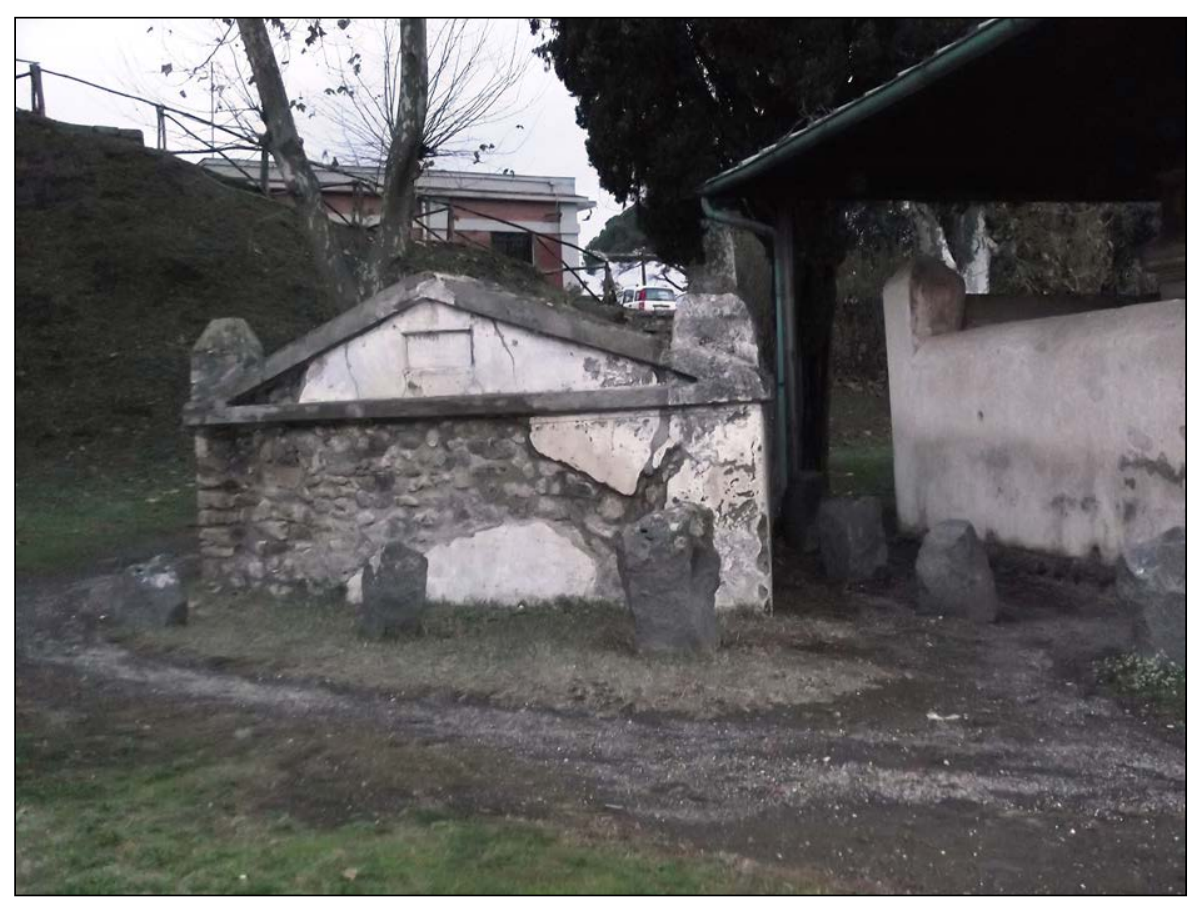

Figura 3. Tumba de Marcus Veius Marcellus. Necrópolis de Porta Vesuvio. Foto: N. Raposo Gutiérrez, 2016. 


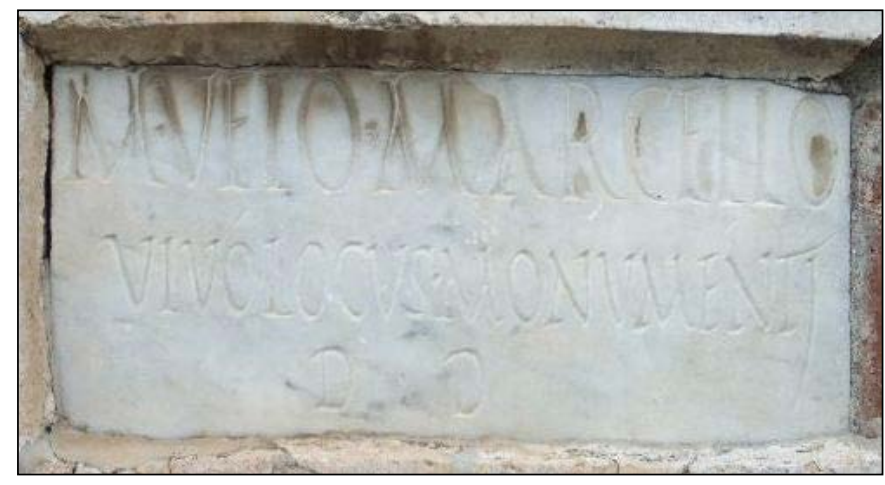

Figura 4. Inscripción tumba de Marcus Veius Marcellus. Necrópolis de Porta Vesuvio. La inscripción reza: M(arco) Veio Marcello / vivo locus monumenti / d(ecreto) d(ecurionum). Traducción: "A Marco Veio Marcello le fue dado el lugar de este monumento por decreto de los decuriones mientras vivía". Foto: N. Raposo Gutiérrez, 2014.

Otra tumba que se encuentra delimitada por una maceria es la tumba PVj (Figuras 2 y 7), perteneciente a Caius Vestorius Priscus, que al igual que la tumba de Marcus Veius Marcellus, también está doblemente delimitada con el muro y rodeada por termini de gran tamaño (Cicirelli, 1998, p. 45; Stefani, 1998, p. 43) (Figura 5). Este sepulcro es uno de los más citados de Pompeya por sus magníficos frescos. Una de estas pinturas contiene una inscripción en mármol flanqueada por dos jóvenes desnudos (Campbell, 2015, p. 202; Cicirelli, 1998, p. 45; Mols y Moormann, 1993, pp. 19-20; Richardson, 1989, p. 363; Schäfer, 1989, p. 389; Spano, 1910, p. 402). En ella se honorifica al edil Vestorius Priscus, que murió posiblemente cuando aún era edil, por lo que la datación de esta tumba sería entre los años 70-76 d.C.

Según se muestra en la inscripción, la ciudad de Pompeya hizo una contribución de 2000 sestercios para el pago de su funeral y puso a disposición el terreno para la

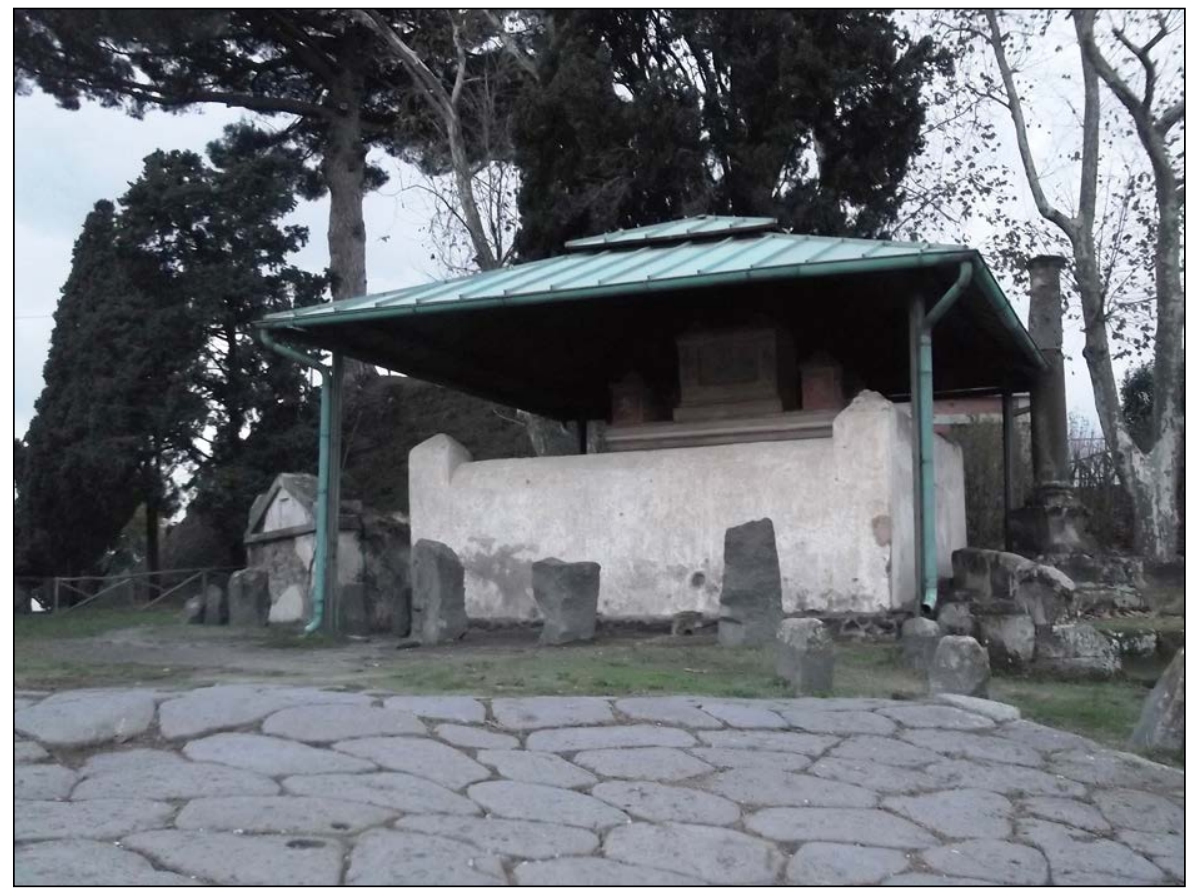

Figura 5. Tumba de Caius Vestorius Priscus. Necrópolis de Porta Vesuvio. Foto: N. Raposo Gutiérrez, 2014. 
sepultura, en tanto que su madre pagó la tumba (Campbell, 2015, p. 202; Cicirelli, 1998, p. 45-46; Mols y Moormann, 1993, p. 22-38; Richardson, 1989, pp. 362-363; Wesch-Klein, 1993, p. 146): C(aio) Vestorio Prisco aedil(i) / vixit annis XXII / locus sepulturae datus et in / funere (sestertium) $d$ (ecreto) $d$ (ecurionum) / Mulvia Prisca mater $p$ (ecunia) $s(\text { ua })^{4}$ $(A E 1911,72$ = AE 1913, 70).

Otro ejemplo lo podemos encontrar en la tumba PVk (Figuras 2 y 7) perteneciente a Arellia Tertulla (Figura 5); este sepulcro está construido a modo de schola como las encontradas en la necrópolis de Porta Ercolano (tumbas de Aulus Veius y de Mamia), en la necrópolis de Porta Nola (tumbas de Aesquillia Polla y la tumba conocida con la sigla PN 3, por no hallarse un epígrafe que indique su propietario), y por último, en la necrópolis de Porta Stabia (tumbas de Marcus Tullius y de Marcus Alleius).

Al igual que el resto de monumentos funerarios hallados en la necrópolis, esta tumba también se encuentra delimitada por termini. Fueron aprovechados por el propietario de la misma, ya que son los que tenían la función de demarcar el ramal del acueducto que pasaba justo frente al sepulcro (Figura 6). Muy posiblemente, tanto la tumba como el acueducto sean contemporáneos, es decir construidos en época augustea, ya que, según los análisis arquitectónicos realizados al sepulcro y el estilo de la columna, parecen pertenecer a un periodo temprano. Sumado a ello, el nombre del marido de la difunta aparece en los grafitos de los muros de la ciudad, por lo que se piensa que la fecha de la tumba podría oscilar entre el 31 a.C. y el 14 d.C. (Campbell, 2015, p. 204; Richardson, 1989, pp. 255-25).

Del mismo modo que la tumba de Caius Vestorius Priscus y del resto de tumbas a modo de schola localizadas en las otras necrópolis de la ciudad, la tumba de Arellia Tertulla contiene una inscripción en la que expone que el lugar en el que se estable

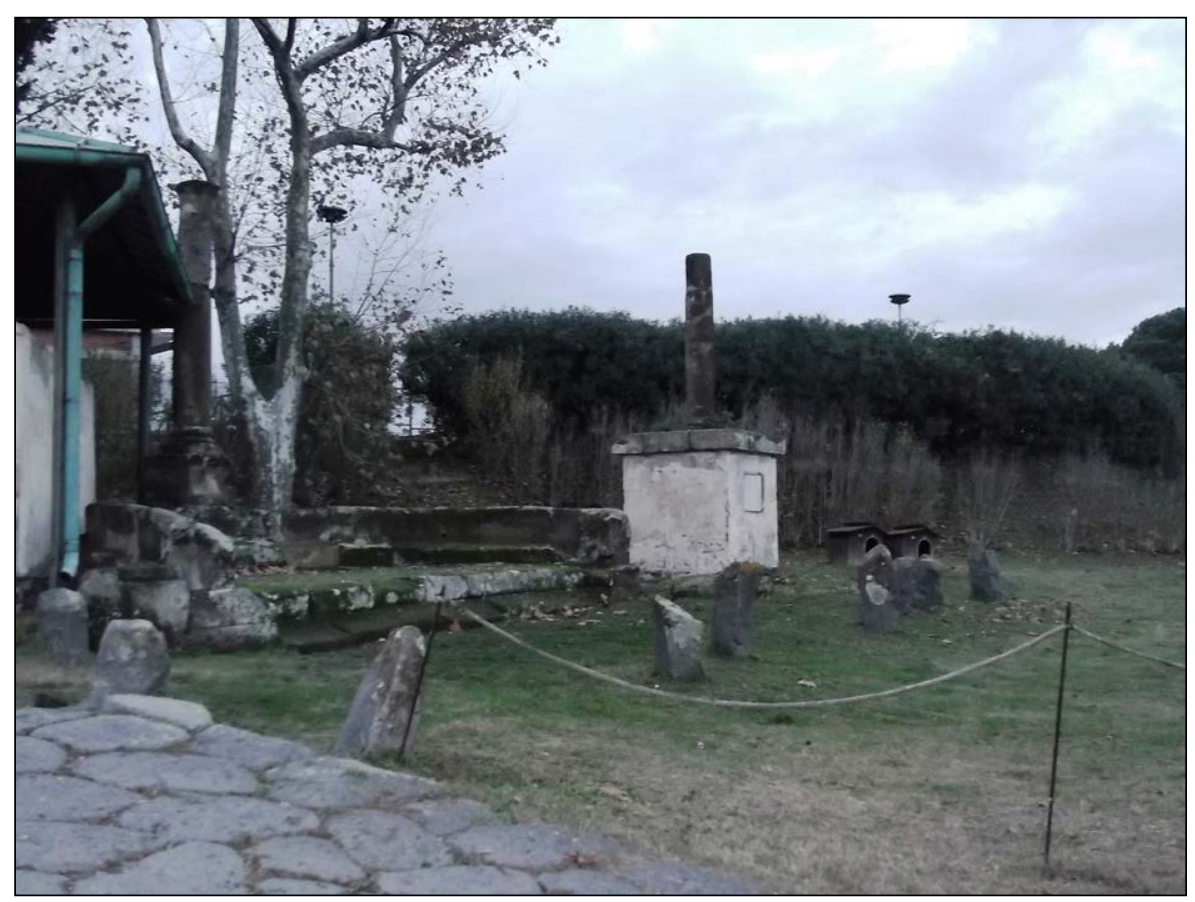

Figura 6. Tumba de Arellia Tertulla. Necrópolis de Porta Vesuvio. Foto: N. Raposo Gutiérrez, 2014.

4 "En la memoria de Caio Vestorio Prisco, edil. Vivió 22 años. Su sepultura se le concedió junto con 2000 sestercios para su funeral por decreto de los decuriones. Su madre Mulvia Prisca (construyó este monumento) con su propio dinero" ( $A E$ 1911, $72=A E$ 1913, 70). 
el monumento funerario fue concedido por los decuriones, y además la ciudad corrió con los gastos del funeral. Debió de ser una ciudadana importante de Pompeya, ya que este tipo de tumbas a modo de schola estaban reservadas a magistrados de la ciudad (Spano, 1910, pp. 404-405). Se piensa que su esposo podría haber sido M. Stlaborius Veius Fronto un magistrado importante de Pompeya, que tuvo su segundo mandando entre los años 25/26 d.C., después del fallecimiento de su esposa (Campbell, 2015, p. 205; Richardson, 1989, pp. 255-256; Stefani, 1998, p. 43; Wesch-Klein, 1993, p. 143), por lo que es posible que éste fuera el motivo por el que su esposa fuera enterrada en un lugar tan destacado y con ese tipo de sepulcro. La inscripción reza: [A]relliae N(umeri) f(iliae) Tertullae / Vei Frontonis huic decurion(es) / locum sepulturae post mortem / dederunt et funus ex $p$ (ecunia) $p$ (ropia) / decre(verunt) $)^{5}$.

Por último, encontramos la tumba PVI (Figuras 2 y 7 ) perteneciente a Septumia. Esta tumba, al igual que la anterior, está delimitada por los termini y, al mismo tiempo, se delimita con los termini del ramal del acueducto (Figura 6). Al igual que la tumba de Tertulla, el estilo de la columna y la aparición del nombre de un candidato a magistrado en los grafitos de los muros de la ciudad (que podrían pertenecer al padre o marido de la fallecida sobre un periodo tardo augusteo), hacen que la fecha de la tumba oscile entre el 31 a.C. y el 14 d.C. (Campbell, 2015, p. 205).

Además de ello, también contiene una inscripción en la que los decuriones dejan testimonio del permiso de erigir la tumba en ese lugar y la colaboración de la ciudad con 2.000 sestercios para el funeral (Spano, 1910, p. 407; Stefani, 1998, p. 43). La inscripción reza: Septumiae $L$ (uci) f(iliae) / d(ecreto) $d$ (ecurionum) / locus sepulturae publice / datus et in funere (sestertium) [duo milia] / Antistia P(ubli) f(ilia) Prima filia / fecit $^{6}$ (AE 1913, 71).

Estas concesiones de los decuriones no se trataban de donaciones a los difuntos por parte de la ciudad, sino que se les dejaban construir en la zona pública como una concesión honorífica. Esta zona, en algunos casos, pertenecía al pomerium de la ciudad, ya que las tumbas se establecían a breve distancia de la puerta de la misma. Este lugar a veces quedaba reservado como espacio público para ubicar allí las tumbas de los magistrados (Kockel, 1983, pp. 12-13; Mols y Moormann, 1993, p. 39; Richardson, 1989, p. 256; Ruiz Osuna, 2019, p. 228). En algunas ocasiones, incluso, la ciudad ayudaba a pagar su construcción o los gastos del sepelio, como reconocimiento público a sus méritos. Esta práctica de conceder a determinados prohombres tales honores era algo habitual en el Imperio Romano (Ruiz Osuna, 2019, p. 228).

En esta necrópolis no se han encontrado inscripciones que hicieran referencia a la definitio pedaturae. Tales medidas serían fijadas por los agrimensores y formarían parte del catastro de la ciudad. Además, se piensa que las necrópolis tenían una estricta organización y eso implicaría cierta vigilancia por parte de las autoridades públicas, por lo que es posible plantear la existencia de un archivo específico destinado al control de tales aspectos (Ruiz Osuna, 2019, p. 220). Desde el punto de vista de la cronología, la dispersión de la práctica destinada a la indicatio pedaturae se establece entre los inicios del principado de Augusto y finales del siglo I d.C. / principios del siglo II d.C., momento en el que comienza a proliferar la costumbre de consagrar los sepulcros a los dei Manes (Ruiz Osuna, 2019, p. 221). Esto no debió ser una coincidencia, sino que el hecho de dedicar a los dei Manes las tumbas pretendía conseguir una consagración más expresa del sepulcro y, con eso, una mayor protección de los mismos (Stylow, 2002,

5 "A la memoria de Arellia Tertullia, hija de Numerio, (esposa) de Veio Fronto, por decreto de los decuriones se le concedió el lugar para el entierro y un funeral pagado con dinero público después de su muerte".

6 "Para Septumia, hija de Lucio, por decreto de los decuriones, se le dio un lugar público para el entierro y 2000 sestercios para su funeral. Antistia Prima, hija de Publio lo hizo (el monumento)" (AE 1913, 71). 
p. 361). Por este motivo, sí aparecen en otras necrópolis de Pompeya inscripciones con referencias a la pedatura, como en las tumbas de Numerius Istacidius y de Numerius Istacidius Helenus en la necrópolis de Porta Ercolano (Raposo Gutiérrez, 2017, pp. 367381) y la tumba de Caius Minatius lucundus en la necrópolis de Porta Nocera (Raposo Gutiérrez, 2017, p. 399). Sin embargo es escaso el número de estas inscripciones, por lo que se piensa que esta práctica no siempre se realizaba e incluso solo se llevaría a cabo en algunos sepulcros que necesitaran de una regulación. En el caso de las tumbas de la necrópolis de Porta Vesuvio, se piensa que no contienen este tipo de inscripciones porque estos monumentos funerarios se situaban en suelo público perteneciente a la ciudad y no era necesario delimitar un espacio que ya estaba acotado para que se establecieran ahí los sepulcros de los magistrados o personas de cierta importancia en la ciudad.

\section{La delimitación del acueducto de Pompeya}

Dentro de la necrópolis de Porta Vesuvio encontramos un elemento de servicio público importante para la ciudad de Pompeya como es el acueducto. En época romana estaba considerado un elemento perteneciente a la ciudad, pero de uso público, por lo que se rige por la misma legislación que los espacios de ocio. Estas obras de ingeniería son consideradas res publicae in publico uso y forman parte de las cosas de derecho humano (res humani iuris), pero con uso público. Además, estos espacios eran calificados como res universitatis, porque eran cosas universales que pertenecían a la comunidad colonial o al municipio (De Marco, 2004, pp. 19-20; Lovato et al., 2014, pp. 251-252; Raposo Gutiérrez, 2018b, p. 114).

El acueducto que suministraba agua a Pompeya era el mismo que abastecía a numerosas ciudades del Golfo de Nápoles. A esta ciudad llegaba un ramal desde el acueducto principal, tradicionalmente denominado Aqua Augusta y también conocido como acueducto del Serino, por el enclave desde donde toma sus aguas, aunque su nombre original fue el de Fontis Augustei Aquaeductus. Este nombre apareció en una inscripción en mármol encontrada en 1936 en Serino. Una inscripción testimonia una restauración que se le realizó al acueducto en época del emperador Constantino, que se data entre el 317-326 d.C. Sin embargo, la construcción es de época augustea, gracias a los análisis realizados a los restos del acueducto, probablemente al periodo comprendido entre 33 y 12 a.C., cuando Marco Vipsania Agrippa era curator aquarum en Roma (Adam y Varène, 2008, p. 47; Camodeca, 1980, p. 62; De Feo y Napoli, 2007, p. 133; Fusco, 2013, p. 85; García Moreno, 2015, p. 151; Olsson, 2015, p. 13; Potenza, 1996, p. 94; Sgobo, 1938, p. 75). La inscripción reza: DD(omini) nn(ostri) FI(avius) Constan/ tinus Max(imus) Pius / Felix Victor Aug(ustus) / et Fl(avius) lul(ius) Crispus et / Fl(avius) Cl(audius) Constantinus / nobb(ilissimi) Caess(ares) / fontis Augustei / aquaeductum / longa incuria / et vetustate conruptum / pro magnificentia / liberalitatis consuetae / sua pecunia refici iusserunt / et usui civitatium infra / scriptarum reddiderunt / dedicante Ceionio Iuliano v(iro) c(larissimo) / cons(ulare) Camp(aniae) curante / Pontiano v(iro) p(erfectissimo) praep(osito) eiusdem / aquaeductus / nomina civitatium / Puteolana Neapolitana Nolana / Atellana Cumana Acerrana / Baiana Misenum (AE 1939, 151).

En las excavaciones que en el año 1900 se estaban efectuando en el Fondo Barbatelli y el Fondo Masucci d'Aquino, en concreto a unos $125 \mathrm{~m}$ de distancia del Castellum Aquae, apareció una sección del acueducto que se dirigía en dirección Norte-Sur hacia la ciudad. Según lo referido en el diario de excavación del 4 de febrero de 1901, el fragmento de canal medía $55 \mathrm{~cm}$ de anchura y una altura de cerca de 1,20 m, unas proporciones semejantes a las que presenta en el punto en que desemboca en el Castellum Aquae. El hallazgo se encontraba muy próximo a los restos de la Villa de $T$. Siminius Stephanus (García Moreno, 2015, p. 154; Stefani, 1995, p. 25). 
En 1910, Giuseppe Spano describe en su diario de excavación el área que se extiende más allá de la Porta Vesuvio, junto a la continuación extramuros de la Via del Vesuvio y a la denominada Via di Circonvallazione, que parece coincidir con la delimitación del pomerium de la ciudad, donde encuentra una serie de bloques de lava fijados verticalmente en el suelo que delatan el curso del canal del acueducto en dirección a la muralla de la ciudad de Pompeya (Spano, 1910, pp. 399-401). En efecto, el trazado del acueducto, documentado mediante la excavación a medio metro de profundidad, puede apreciarse paralelo a la Via del Vesuvio, provocando un elevamiento característico de las losas del suelo, junto a la Tumba de Vestorius Priscus (Ohlig, 2001, p. 392).

Por lo tanto, como podemos observar en el plano de Spano (Figura 7), localizamos el último tramo del acueducto que llega a la ciudad en la necrópolis de Porta Vesuvio. Este canal está ubicado entre el pedestal del tribuno Titus Suedius Clemens (PVa) (Raposo Gutiérrez, 2017, p. 83; Raposo Gutiérrez, 2018a, p. 19) y las tumbas de Septumia y de Arellia Tertulla. Este trozo de acueducto estaba delimitado por diez termini, como en su día defendió Spano, alineados en paralelo por donde circulaba bajo tierra el specus del acueducto (Figura 8) (Ohlig, 2001, p. 96; Spano, 1910, p. 400). Además, en el plano de Spano vemos tres termini cerca de la muralla, que posiblemente delimitaban la continuación del specus del acueducto justo antes de conectar con el Castellum Aquae (Ohlig, 2001, p. 144; Spano, 1910, p. 400). Sin embargo, en la actualidad no contamos con estos termini en su lugar de origen y no sabemos el momento ni el motivo por los que fueron movidos de su ubicación.

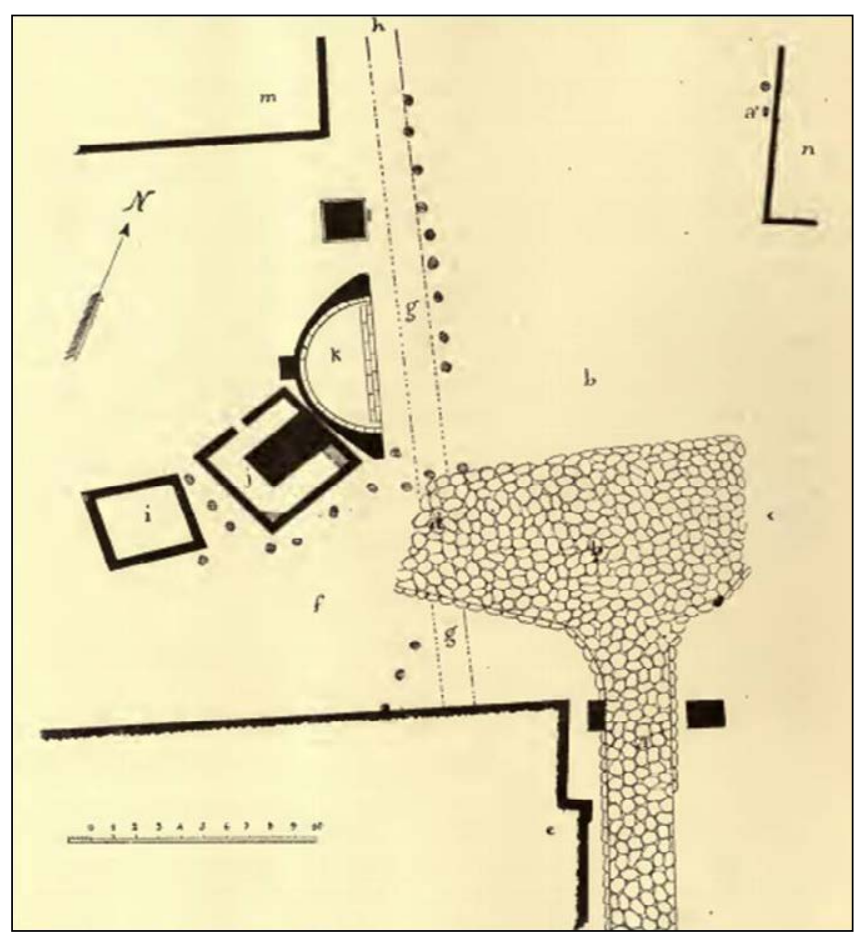

Figura 7. Plano de la necrópolis de Porta Vesuvio con los termini. Tomado de Spano (1910, p. 400).

Además, cuando se estaba excavando el Fondo Masucci d'Aquino, surgió una parte del acueducto delimitado por dos piedras, lo que se interpretó como dos cipos distantes 4 $m$ uno del otro, que señalaban el suelo público por donde pasaba el acueducto (Stefani, 1995, p. 25); por ello, podemos pensar que el ramal del acueducto en todo el tramo que estaba bajo tierra posiblemente estaba delimitado con termini. 


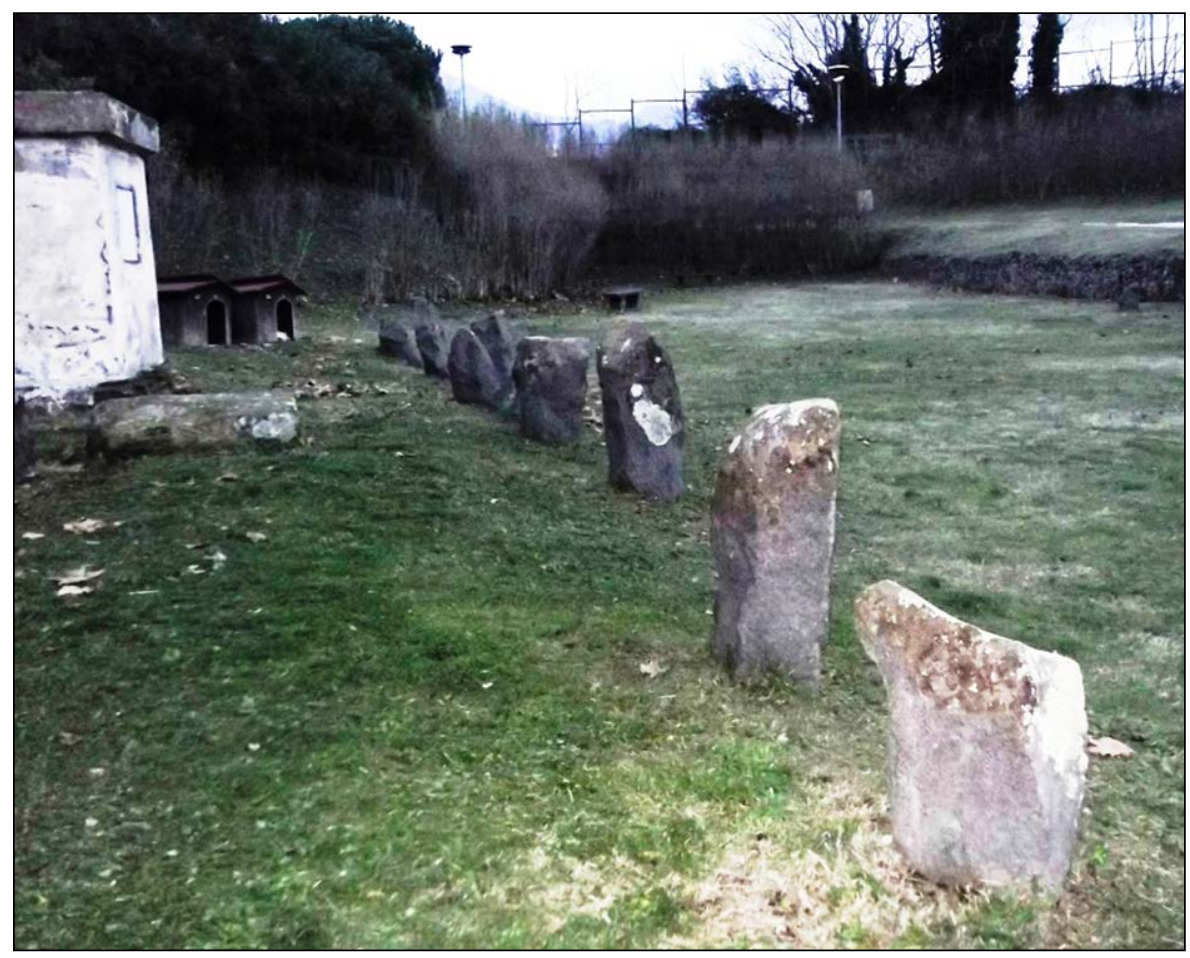

Figura 8. Termini delimitando el acueducto de Pompeya. Necrópolis de Porta Vesuvio. Foto: N. Raposo Gutiérrez, 2014.

El acueducto, como se ha comentado, se conectaba al Castellum Aquae o castellum divisorium, situado en la Porta Vesuvio dentro de las murallas de la ciudad justo en el punto más alto. Se estableció en esa zona ya que es ahí donde llega el ramal del acueducto, por lo que se piensa que el castellum divisorium es de época augustea como el acueducto. La función de este edificio era la de dividir el agua procedente del acueducto. Esta división del agua se realizaba en el interior del edificio y se dividía en tres compartimentos para luego distribuirla a la ciudad por medio de tuberías que iban a desembocar a las distintas torres de agua o castella divisoria, y desde ellas se distribuía el agua hacia las fuentes, las termas y las viviendas de los ciudadanos que disponían de agua corrientes en sus casas (Adam y Varène, 2008, p. 39; De Vos y De Vos, 1982, p. 174; Etienne, 1971, p. 302; García Moreno, 2015, p. 88; Jasen, 2007, p. 260; Maiuri, 1950, p. 53; Olsson, 2015, p. 15; Raposo Gutiérrez, 2018a, p. 215; Richardson, 1989, pp. 55-56).

Por el lado opuesto a la conexión del acueducto al castellum divisorium, encontramos la salida de las tuberías para distribuir el agua a la ciudad. Justo en esa zona Sur del edificio se observa un espacio abierto, que posiblemente se realizó con el fin de que el área ubicada delante de la puerta contara con espacio para el tránsito de vehículos y peatones $\sin$ formarse atascos en un sector que debía de ser muy transitado, ya que era una entrada o salida de la ciudad y donde se encontraban distintos comercios. Además, podemos comprobar cómo el edificio del castellum divisorium estaba rodeado, en el lado meridional, por siete termini de piedra volcánica y de medidas irregulares semejantes a los que delimitan el acueducto (Figura 9). Estos mojones, según algunos autores, tenían la función de proteger el edificio de los posibles golpes recibidos por el tránsito de carros (Adam y Varène, 2008, p. 50). Sin embargo, defendemos que no solo tendrían una función de protección, sino que su misión principal era la de delimitar la zona ya que el Castellum Aquae era un edificio de servicio público de la ciudad y, al igual que las fuentes públicas o las torres de agua, debían estar demarcados para diferenciar el espacio público del privado, y así no ser invadido (Raposo Gutiérrez, 2018a, p. 217). 


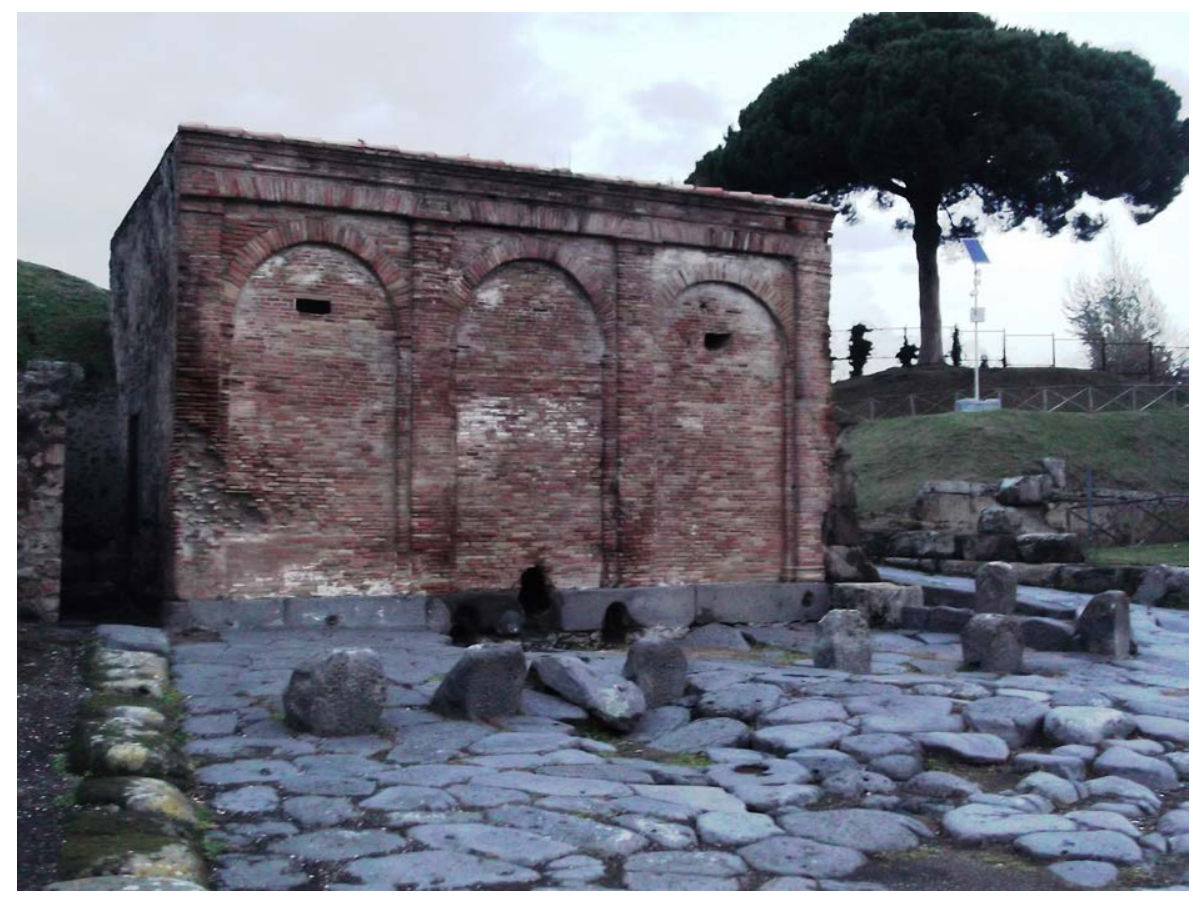

Figura 9. Termini delimitando el Castellum Aquae de Pompeya. Foto: N. Raposo Gutiérrez, 2014.

La función de estos termini, tanto del acueducto como del Castellum Aquae, era la de demarcar los elementos públicos de la ciudad. En el caso del acueducto no podía ser menos, así que estaban señalando que en esa zona no estaba permitido realizar construcciones por estar dentro de una de las necrópolis de la ciudad y, aunque los particulares o la ciudad podrían construir en esa área, la zona debía permanecer libre de construcciones para no dañar el acueducto.

En Pompeya no hemos encontrado ningún cipo o terminus epigráfico en el que se muestre información sobre el acueducto y su delimitación. Por un lado, pensamos que en este tramo del acueducto no se estableció este terminus, que estaría en otra zona o ciudad; en este sitio solo fueron puestos los termini delimitadores del espacio. Por otro lado, es posible que este cipo sí hubiera existido y se hubiera perdido durante las excavaciones de principios del siglo XX; incluso cabe la posibilidad de que lo que se haya perdido haya sido la inscripción de uno de los termini que delimitan el acueducto.

Sin embargo, en otras ciudades del Imperio se han hallado estos termini epigráficos, y nos dan una idea de cómo podría haber sido el terminus del acueducto del Serino. Contamos con ejemplos de termini o pedestales epigráficos en algunos acueductos como en Mevania (Bevagna), Tusculum (Roca Priora) o también en las provincias como en Lugdunum (Lyon). Tomamos como ejemplo los termini a modo de pedestales hallados en el acueducto de Gier en Lugdunum, porque cuentan con una inscripción muy significativa: Ex auctoritate / Imp(eratoris) Caes(aris) Traia/ni Hadriani / Aug(usti) nemini / arandi ser/endi pang/endiue ius / est intra id / spatium ag/ri quod tute/lae ductus / destinatum / est (CIL XIII, 1623; $A E$ 1888, 31). En esta inscripción se aprecia cómo el emperador Adriano indicó la zona de protección alrededor de uno de los cuatro acueductos de la ciudad de Lugdunum, el acueducto de Gier. El texto detalla las acciones prohibidas en dicho espacio: nadie podía arar, cultivar o plantar y el área estaba reservada para la protección y conservación del acueducto. Esta información es poco frecuente en este tipo de epígrafes (Cortés Bárcena, 2013, p. 267; Cortés Bárcena, 2019, p. 247). 
Otro tipo de cipos que se han hallado son los de los acueductos de Anio Vetus y de Marcia en Roma. Estos cipos o termini se encontraron a lo largo del recorrido de los acueductos a una cierta distancia unos de otros con una serie de inscripciones que aportan información sobre la longitud del acueducto. Por un lado, los cipos del acueducto Anio Vetus contienen inscripciones idénticas, excepto algunas variaciones en el patrón que sigue el epígrafe y en la medida respecto a la distancia de un cipo a otro. En ella aparece el nombre del acueducto seguido del nombre del emperador Augusto, después aparece el número de orden y la distancia del cipo precedente en pies: Ani(o) Imp(erator) Caesar, Divi f(ilius), August(us), ex s(enatus) c(onsulto), C(M) XXIV, p(edes) CCXL (AE 1957, 1983) (Mari, 1991, p. 152). Por otro lado, los cipos del acueducto Marcia, como ocurre con el acueducto Anio Vetus, contienen inscripciones idénticas; además, las inscripciones de estos termini son parecidas a las de Anio Vetus y solo cambia el nombre del acueducto. Por tanto, aportan la misma información: Mar(cia), Impe(rator) Caesar, Divi f(ilius), Augustus, ex s(enatus) c(onsulto), MC[L]XXIV, p(eduum) CCXI (AE 1953, 0070) (Mari, 1991, p. 157).

Además de los cipos con inscripciones vinculados a los acueductos contamos con la existencia de la inscripción de la Tabula Acquaria Venafrana. Esta inscripción contiene un edicto augusteo (11-9 a.C.) relativo a la regulación del acueducto de Venafro, y fue hallada en Isernia (Italia). En la parte que se conserva, el edicto regula, entre otras cosas, la manutención, reparación y restauración del acueducto, la obligación y el deber de los vecinos de abstenerse de ocupar el área perteneciente el acueducto, y asigna a los duoviri el deber de vigilar que esto se cumpliera (Fusco, 2013, pp. 69-77; Garrucci, 1852, pp. 21-34; Maganzani, 2012, pp. 125-130).

A pesar de que estos tipos de cipos epigráficos no se hayan hallado en Pompeya o sus proximidades hasta el día de hoy, no quiere decir que el acueducto del Serino no contara con ellos. Estos ejemplos localizados en distintas ciudades demuestran que algunos acueductos romanos contaban con una clara y estricta legislación de su espacio para que este no fuera invadido con ninguna construcción o actividad alguna, al igual que ocurría con otros elementos públicos en los espacios urbanos de las ciudades?.

\section{Conclusiones}

A la hora de delimitar los distintos espacios, la zona suburbana de la ciudad comparte un sistema semejante al de la zona interna de la misma. Las tumbas siguen la norma de demarcación de espacios con los termini. Sin embargo, algo que es bastante significativo en la necrópolis de Porta Vesuvio es que las tumbas no están rodeadas por aceras como ocurre en el resto de necrópolis de la ciudad; se ha pensado que esto es posible porque esta necrópolis no está excavada en su totalidad y aún falta una gran área por descubrir, en la que podría hallarse un acerado.

Los monumentos funerarios destacan por su forma de delimitación semejante a la demarcación que tienen los elementos de servicios públicos de la ciudad, como las fuentes de agua, los castella aquae castella secundaria, el Castellum Aquae o las plazas de la ciudad rodeados por una serie de termini.

Se piensa que la legislación romana ve como un delito más grave el hecho de invadir un monumento funerario que un edificio público, y es posible fundamentar esta afirmación en el hecho de que las tumbas cuentan con una doble y a veces triple delimitación con los termini insertos en los bordillos de las aceras, los termini o las maceriae que rodean los propios sepulcros y los propios termini con la definitio pedaturae. Si bien es cierto

7 Para más detalles ver Raposo Gutiérrez (2018a). 
que no encontramos ningún ejemplo de la pedatura de las tumbas en la necrópolis de Porta Vesuvio, sí las localizamos en otras necrópolis como en la de Porta Ercolano o Porta Nocera, aunque en un número escaso. Por ello, se piensa que esta práctica se realizaría en algunos sepulcros que necesitaran de una regulación más fuerte. En el caso de las tumbas de la necrópolis de Porta Vesuvio, se cree que no contienen este tipo de inscripciones porque estos monumentos funerarios se situaban en suelo público perteneciente a la ciudad, concretamente en el pomerium, ya que a algunas personas de cierto protagonismo se le concedían privilegios a la hora de establecer sus sepulcros, pudiendo éstos situarse en un espacio público concedido por decreto decurionum, tal y como figura en las inscripciones asociadas a estas tumbas. Por este motivo, no era necesario delimitar un espacio que ya estaba acotado para que se establecieran en él los sepulcros de estas personas, como se encuentran en el resto de necrópolis de la ciudad e incluso en otros lugares públicos como es el caso del Foro Civil, donde se establecieron algunos elementos honoríicos a ciertas personas de ciudad, o también en los templos.

De igual manera, encontramos un elemento de servicio público, el acueducto, que sigue la norma de delimitación de espacios por los termini. Se aprecia como éstos están dispuestos longitudinalmente recreando en superficie el trazado del acueducto que se localiza en el subsuelo de la necrópolis. El acueducto se encuentra delimitado para que no se pueda establecer construcción sobre él. A pesar de que se encuentre bajo tierra, la zona por la que pasa es suelo público y por ello susceptible de ser invadida; al no verse el trazado del acueducto, lo más recomendable era delimitar con termini su trazado debido a que, en este caso en particular, este elemento de servicio público no se observa en superficie y su invasión podría ocurrir incluso sin darse cuenta el ciudadano. Por ello, con este sistema podían señalizarlo para que no fuera susceptible de ser usurpado fácilmente por los particulares con la construcción - en este caso de los monumentos funerarios -, ya que, como hemos visto, en otros acueductos del Imperio se han encontrado una serie de inscripciones en las que se regulaba estrictamente la delimitación y la protección del área adyacente de los acueductos.

Para finalizar, se ha llegado a la conclusión que Pompeya sigue la norma legal de delimitación de espacios en su urbanismo suburbano. Aunque en algunos casos los particulares establecieran sus sepulcros en el pomerium, esto acontecía en circunstancias particulares con permiso de los magistrados. En esta necrópolis no contamos, a día de hoy, con usurpaciones de espacio público, como ocurre en la necrópolis de Porta Ercolano o en las zonas urbanas de la ciudad. Por consiguiente, Pompeya es una ciudad que nos permite conocer cuál era la norma por la que se regía en época romana la delimitación de los loca religiosa durante todo el siglo I d.C. y, como en el caso en particular, hasta el año 79 d.C.

\section{Agradecimientos}

Agradezco a la Soprintendenza Archeologica di Pompei por permitirme llevar a cabo las investigaciones sobre los espacios públicos en Pompeya. Agradezco a todas aquellas personas que de una forma u otra contribuyeron en la realización de este trabajo. Parte de este trabajo se llevó a cabo durante una estancia de investigación en Italia financiada por la Unión Europea, Programa Erasmus+ y la Universidad Complutense de Madrid. Por último, agradezco a los evaluadores anónimos que con sus comentarios contribuyeron a mejorar este manuscrito. 


\section{Q Referencias citadas}

» Adam, J. P. y Varène, P. (2008). Le Castellum Aquae de Pompéi. Étude architecturale. Revue Archéologique, 1, 37-72.

» Camodeca, G. (1980). Ricerche su Puteoli tardoromana (fine III-IV secolo). Puteoli, Studi di storia antica, 4-5, 59-128.

» Campbell, V. (2015). The tombs of Pompeii: organization, space and society. Nueva York: Routledge.

» Carroll, M. (2006). Spiritis of the Dead: Roman Funerary Commemoration in Western Europe. Oxford: Oxford University Press.

» Castillo Pascual, M. J. (2011). Espacio en orden: El modelo gromático-romano de ordenación del territorio. Logroño: Universidad de La Rioja.

» Cenerini, F. (2005). L'indicazione della pedatura nelle iscrizioni funerarie romane dell'Emilia Romagna (Regio VIII). En G. Cresci Marrone y M. Tirelli (Eds.), Terminavitsepulcrum. I recinti funerari nelle necropoli di Altino. Atti del convegno Venezia 3-4 dicembre 2003 (pp. 137-143). Roma: Edizioni Quasar.

» Cicerón (2009). Las Leyes. Biblioteca Clásica Gredos 381. Madrid: RBA.

» Cicirelli, C. (1998). La tomba di Vestorio Prisco. En P. Guzzo (Ed.), Pompei oltre la vita: nuove testimonianze dalle necropoli (pp. 45-49). Pompeya: Soprintendenza Archeologica di Pompei.

» Clarke, J. (2003). Art in the Lives of Ordinary Romans: Visual Representation and Non-Elite Viewers in Italy, 100 BC-AD 315. Berkeley: University of California Press.

» Cooley, M. y Cooley, A. E. (2004). Pompeii. A sourcebook. Nueva York: Routledge.

»Cortés Bárcena, C. (2013). Límites territoriales monumentalizados, los termini publici de la Gallia Narbonensis. En J. M. Iglesias Gil y A. Ruiz Gutiérrez (Eds.), Paisajes epigráficos de la Hispania romana. Monumentos, contextos, topografía (pp. 267-285). Sevilla: L'Erma di Bretschneider.

»Cortés Bárcena, C. (2019). La visibilización de los confines en las provincias occidentales. En R. Dubbini (Ed.), I confine di Roma. Atti del convegno internazionale (Università degli Studi di Ferrara, 31 maggio - 2 giugno 2018) (pp. 241-252). Pisa: Edizioni ETS.

» D’Ambrosio, A. (2001-2002). Ufficio Scavi di Pompei. Rivista di Studi Pompeiani, 12-13, 219221.

》 D’Ors, A. (1975). El digesto de Justiniano. Pamplona: Aranzadi.

» Daremberg, C., Saglio, E. y Pottier, E. (1877-1919). Dictionnaire des Antiquités Grecques et Romaines, d'après les textes et les monuments contenant l'explication des termes qui se rapportent aux mœurs, aux institutions, à la religion et en général à la vie publique et privée des anciens, 5(1). Paris: Reimpr. Graz.

» De Feo, G. y Napoli, R. M. A. (2007). Historical development of the Augustan Aqueduct in Southern Italy: twenty centuries of works from Serino to Naples. Water Science \& Technology: Water Supply, 7, 131-138.

» De Marco, N. (2004). I loci publici dal I al III secolo. Le identificazioni dottrinali, il ruolo dell'usus, gli strumenti di tutela. Nápoles: Satura.

»De Visscher, F. (1963). Le droit des tombeaux romains. Milán: Giuffré.

» De Vos, A. y De Vos, M. (1982). Guide Archeologiche di Laterza. Pompei, Ercolano, Stabia vol. 11. Roma-Bari: Laterza.

»Emmerson, A. L. C. (2011). Evidence for Junian Latins in the tombs of Pompeii? Journal of Roman Archaeology, 24, 161-190. 
» Etienne, R. (1971). La vida cotidiana en Pompeya. Madrid: Aguilar.

» Fusco, A. (2013). La gestione dell'acqua nelle civitates dell'Italia romana. La documentazione epigrafica. (Tesis doctoral), Università degli Studi di Palermo, Italia.

» García Moreno, C. (2015). Arqueología del acueducto de Serino en Campania y su conexión con Pompeya. En J. García Sánchez, I. Mañas Romero y F. Salcedo Garcés (Eds.), Navigare necesse est. Estudios en homenaje a José María Luzón Nogué (pp. 151-157). Madrid: Universidad Complutense de Madrid.

»Garrucci, R. (1852). Tavola aquaria Venafrana. Bullettino Archeologico Napoletano, 3, 21-34.

»Gregori, G. (2005). Definizione e misurazione dello spazio funerario nell'epigrafia repubblicana e protoimperiale di Roma. Un'indagine campione. En G. Cresci Marrone y M. Tirelli (Eds.), Terminavit sepulcrum. I recinti funerari nelle necropoli di Altino. Atti del convegno Venezia 3-4 dicembre 2003 (pp. 77-126). Roma: Edizioni Quasar.

"Hermon, E. (2017). Les loca sacra dans le Corpus agrimensorum romanorum (CAR). Cahiers des etudes ancienns, 54, 69-93.

» Jacobelli, L. (2001). Pompei fuori le mura: note sulla gestione e l'organizazione dello spazio pubblico e privato. En F. Senatore (Ed.), Pompei tra Sorrento e Sarno. Atti del terzo e quarto ciclo di conferenze di geologia, storia e archeologia. Pompei, gennaio 1999-maggio 2000 (pp. 29-61). Roma: Scienze e Lettere.

» Jasen, G. (2007). The water system. Supply and drainage. En J. J. Dobbins y P.W. Foss (Eds.), The world of Pompeii (pp. 257 266). Londres: Routledge.

» Kockel, V. (1983). Die Grabbauten vor dem Herkulaner Tor in Pompeji. Mainz: Zabern.

» Lassère, J. M. (2005). Manuel d'Épigraphie Romaine I: L'individu - La cite. París: Picard.

» Lazzarini, S. (2005). Regime giuridico degli spazi funerari. En G. Cresci Marrone y M. Tirelli (Eds.), Terminavit sepulcrum. I recinti funerari nelle necropoli di Altino. Atti del convegno Venezia 3-4 dicembre 2003 (pp. 47-57). Roma: Edizioni Quasar.

» Ling, R. (2005). Pompeii: History, Life and Afterlife. Stroud: Tempus.

» Lovato, A., Puliatti, S. y Solidoro Maruotti, L. (2014). Diritto privato romano. Turín: G. Giappichelli Editore.

» Maganzani, L. (2012). Edictum Augusti de aquaeductu Venafrano. En G. Purpura (Ed.), Revisione ed integrazione dei Fonte luris Romani Anteiustiniani I (pp. 125-134). Turín: G. Giappichelli Editore.

» Maiuri, A. (1950). Pompeya. Las nuevas excavaciones. La Villa de los Misterios. El Antiquarium. Roma: La Libreria dello Stato.

» Mari, Z. (1991). Nuovi cippi degli acquedotti aniensi. Considerazioni sull'uso dei cippi acquari. Papers of the British School at Rome, 59, 152-175.

» Mau, A. (1908). Pompeji in Leben und Kunst. Leipzing: W. Engelmann.

» Moatti, C. (1992). Étude sur l'occupation des terres publiques à la fin de la République Romaine. Cahiers du Centre Gustave Glotz, 3, 57-73.

» Mols, S. T. y Moormann, E. M. (1993). Ex parvo crevit: Proposta per una lettura iconografica della Tomba di Vestorius Priscus fuori Porta Vesuvio a Pompei. Rivista di Studi Pompeiani, 6, 15-52.

» Mommsen, T. (1899). Derecho penal romano. [Trad. P. Dorado Montero, 1999]. Santa Fe de Bogotá: Editorial Temis.

»Ohlig, C. P. J. (2001). De aquis Pompeiorum: Das Castellum Aquae in Pompeji, Circumvesuviana (Volumen 4). Amsterdam: Bod-Books on Demand.

» Olsson, R. (2015). The water-supply system in Roman Pompeii. (Tesis de Licenciatura inédita), Lund University, Suecia.

»Potenza, U. (1996). Gli acquedotti romani di Serino. Annual Papers on Classical Archaeology, 4, 93-100. 
» Raposo Gutiérrez, N. (2015). Las aceras de Pompeya. En M. Calderón Sánchez, S. España Chamorro y R. Montoya González (Eds.), Estudios Arqueológicos del área Vesuviana I (pp. 102-112). Oxford: BAR.

» Raposo Gutiérrez, N. (2017). La delimitación de los espacios públicos en Pompeya. (Tesis doctoral inédita), Universidad Complutense de Madrid, España.

» Raposo Gutiérrez, N. (2018a). La delimitación de los espacios públicos en Pompeya. Oxford: BAR.

》 Raposo Gutiérrez, N. (2018b). La delimitación de los espacios de defensivos en Pompeya. En III Jornadas de Jóvenes Investigadores en Arqueología (pp. 113-123). Madrid: Asociación Jóvenes Investigadores en Arqueología. Excavemos.

» Raposo Gutiérrez, N. (2018c). La delimitación de los espacios de ocio en Pompeya. Onoba, $6,113-123$.

» Richardson, L. (1989). Pompeii: an architectural history. Londres: Baltimore.

» Ruiz Osuna, A. (2019). De sua pecunia. El paisaje socio-económico de las necrópolis romanas. Apuntes sobre Hispania. Madrider Mitteilungen, 60, 215-245.

»Schäfer, T. (1989). Imperii insignia. Sella curulis und fasces: zur Repräsentation römischer Magistrate. Römische Mitteilungen 29. Berlín: P. Zabern.

»Sgobo, I. (1938). L'acquedotto romano della Campania: Fintis Augustei Aquaeductus. Notizie degli scavi di Antichita, 14, 75-97.

》Sogliano, A. (1899). Fabbriche antiche scoperte in contrada "Civita" presso le mura di Pompei. Notizie degli scavi di Anichità, 236-239.

»Spano, G. (1910). Scavi fuori Porta del Vesuvio. Notizie degli scavi di Antichità, 7, 399-418.

» Stefani, G. (1995). Contributo alla carta archeologica dell'ager pompeianus. I rinvenimenti presso Porta Vesuvio. Rivista di Studi Pompeiani, 7, 11-33.

»Stefani, G. (1998). La necropoli di Porta Vesuvio. En P. Guzzo (Ed.), Pompei oltre la vita: nuove testimonianze dalle necropoli (p. 43). Pompeya: Soprintendenza Archeologica di Pompei.

"Stylow, A. (2002). La epigrafía funeraria en la Bética. En D. Vaquerizo (Ed.), Espacios y usos funerarios en el Occidente Romano. Actas del congreso internacional celebrado en la Facultad de Filosogía y Letras de la Universidad de Córdoba, 5-6 de junio de 2001 (pp. 353-368). Córdoba: Universidad de Córdoba, Seminario de Arqueología.

» Toynbee, J. (1971). Death and Burial in the Roman World. Londres: JHU Press.

» Vaquerizo, D. y Sánchez, S. (2008). Entre lo público y lo privado. Indicatio Pedaturae en la epigrafía funeraria Hispana. Archivo Español de Arqueología, 81, 101-131.

» Von Hesberg, H. (2005). II recinto nelle necropoli di Roma in età repubblicana: origine e diffusione. En G. Cresci Marrone y M. Tirelli (Eds.), Terminavitsepulcrum. I recinti funerari nelle necropoli di Altino. Atti del convegno Venezia 3-4 dicembre 2003 (pp. 59-75). Roma: Edizioni Quasar.

»Wesch-Klein, G. (1993). Funuspublicum: eine Studium zuröffentlichen Beisetzung und Gewährung von Ehrengräbern in Rom und den Westprovinzen (Volumen 14). Stuttgart: F. Steiner. 